\title{
EXCESSIVA ONEROSIDADE SUPERVENIENTE: UMA ANÁLISE À LUZ DA JURISPRUDÊNCIA DO SUPERIOR TRIBUNAL DE JUSTIÇA
}

Silas Silva Santos, Geovanna Carrijo dos Santos Dalefi Andrade, Thaiza Akemi Pereira, Fernando da Costa Machado Filho, Leticia Rodrigues Biassoti

Universidade do Oeste Paulista - UNOESTE, Curso de Direito, Presidente Prudente, SP. E-mail: silas@unoeste.br

\section{RESUMO}

O presente artigo busca refletir sobre as teorias que fundamentam a aplicação da onerosidade excessiva superveniente no ordenamento jurídico brasileiro à luz de casos decididos pelo Superior Tribunal de Justiça, investigando a importância da jurisprudência na aplicação do tema. A metodologia empregada é a qualitativa atrelada ao método dialético, com o uso do levantamento de dados por meio da pesquisa bibliográfica e aplicação do raciocínio de silogismo. Observou-se que as partes devem considerar os riscos existentes no negócio jurídico estabelecido, para que a teoria da imprevisão seja aplicada de maneira subsidiária, prevalecendo-se a autonomia da vontade.

Palavras-chave: Onerosidade Excessiva Superveniente. Teoria da Imprevisão. Revisão Contratual. Jurisprudência do STJ.

\section{SUPERVENING EXCESSIVE ONEROSITY: AN ANALYSIS IN THE LIGHT OF THE JURISPRUDENCE OF THE SUPERIOR COURT OF JUSTICE}

\begin{abstract}
This article seeks to reflect on the theories that justify the application of the supervening excessive onerosity in the Brazilian legal system in the light of cases decided by the Superior Court of Justice, investigating the importance of the jurisprudence in the application of the studied. The qualitative research is applied with the use of the dialectical method and data collection through bibliographic research, also using the syllogism reasoning. It was observed that the contracting parties should consider the existing risks in the legal business, so that the theory of unpredictability is applied in a subsidiary manner, prevailing the autonomy of will.

Keywords: Supervenient Excessive Onerosity. Theory of Unpredictability. Contractual revision. The Superior Court of Justice (STJ) jurisprudence.
\end{abstract}

\section{INTRODUÇÃO}

O Direito contemporâneo é concebido como aquele decorrente das transformações sociais, da evolução teórica, da reflexão e sobretudo da construção jurisprudencial acerca de temas relevantes e indispensáveis para a harmonia da sociedade. Nessa perspectiva também se encontra o Direito Civil, utilizado neste momento de forma genérica, como a área disciplinadora das relações jurídicas de natureza privada e travadas entre sujeitos em nível de paridade.

Nesse contexto, destaca-se a autonomia privada, consistente no poder de os sujeitos livremente estabelecerem seus negócios jurídicos, buscando a satisfação de seus mútuos interesses. Para garantir a segurança desses pactos incide a noção de força obrigatória dos contratos, cujo conteúdo torna-se lei entre os pactuantes e, por isso mesmo, fica imune à intervenção estatal, ao menos como regra. 
Ocorre que nem sempre os desdobramentos da relação contratual são os almejados; questões incidentais podem surgir, provocando desequilíbrio entre os contratantes e impedimentos quanto ao adimplemento correto do acordado. Não raras vezes sobrevém uma onerosidade excessiva capaz de gerar a extinção anormal do negócio, situação que, de certa forma, mitiga aquela noção de obrigatoriedade dos contratos.

Essa possibilidade de extinção dos contratos em razão de causas supervenientes convive, porém, com outro noção muito cara para o Direito Civil, que é a conservação dos negócios jurídicos. Daí que medidas equitativamente pensadas podem ser adotadas para obstar a resolução, restaurando-se o equilíbrio contratual perturbado por causas supervenientes. Desse modo, o objetivo do presente artigo é refletir sobre as teorias que fundamentam a aplicação da onerosidade excessiva superveniente no ordenamento jurídico brasileiro à luz de casos decididos pelo Superior Tribunal de Justiça, investigando a importância da jurisprudência na aplicação do tema.

Adota-se essa postura investigativa diante da percepção de que os casos anteriores, julgados por uma Corte Superior, podem iluminar os rumos de futuras decisões que versem sobre os possíveis desequilíbrios surgidos em razão da pandemia de Covid-19, mesmo porque é missão dos tribunais manter a estabilidade, a integridade e a coerência de sua jurisprudência.

\section{MÉTODO}

Este artigo, do ponto de vista metodológico, vale-se da abordagem qualitativa, uma vez que a compreensão do tema não se dá por meio da análise de números e dados quantificáveis; a pesquisa é descritiva e subjetiva, de modo que a inteligência dos fenômenos ocorre com base na aferição da relevância da bibliografia coletada.

Atrelado a tal abordagem, aplica-se o método dialético, mediante a síntese de proposições díspares sobre o assunto abordado, haja vista que "[...] sempre existirá uma luta entre os contrários, os quais se excluem, mas ao mesmo tempo estão unidos" (MEZZAROBA; MONTEIRO, 2019, p. 97).

Para realizar o levantamento de dados utiliza-se a pesquisa bibliográfica, buscando explicar e discutir o tema idealizado com base em artigos científicos, doutrinas jurídicas relevantes, legislação nacional etc.; ou seja, todo o material produzido que se encontra para livre acesso do pesquisador, sem prejuízo da investigação de jurisprudência que revele as fundamentações adotadas nos casos reais julgados pelo Poder Judiciário (MARCONI; LAKATOS, 2019).

Para tanto, aplica-se o raciocínio de silogismo, que se constitui a partir de duas premissas (maior e menor) e de uma conclusão (HENRIQUES; MEDEIROS, 2017). No presente trabalho as normas e as teorias representam a premissa maior; os fatos, a premissa menor; e a conclusão, pela legislação, demonstra-se com a aplicação prática do Direito, observada nas fundamentações dos julgados.

\section{DISCUSSÃO}

Os fundamentos da onerosidade excessiva: teoria da imprevisão

A teoria da imprevisão tem como desígnio relativizar o pacta sunt servanda, frente às modificações objetivas do contrato, pela superveniência de fato que o torne excessivamente oneroso a uma das partes ou a ambas.

O Código Civil de 1916, na esteira do Código Civil francês de 1804, não contemplou a hipótese de modificação ou resolução do contrato pela excessiva onerosidade superveniente, já que os diplomas foram forjados sob a égide irredutível do princípio da força obrigatória dos contratos, em respeito à vontade das partes e à noção da mínima intervenção estatal na autonomia privada. O retrato social vigente era de um Estado Liberal Clássico, razão pela qual a liberdade absoluta de contratar constituía ideal intocável de justiça, frente aos arroubos de um pretérito Estado Absolutista. Portanto, a propriedade privada e a liberdade de contratar eram pilares sagrados do Estado de Direito vigente.

De fato, o prestígio à segurança jurídica, a força obrigatória dos contratos e o próprio princípio da legalidade serviram de escudo aos que defendiam a impossibilidade de aplicação do instituto, rechaçando-se qualquer forma de intervenção do Estado no contrato. Nesse sentido, parcela da doutrina defendia que o Estado-Juiz não poderia criar novas condições contratuais ou mesmo impor a resolução do pacto antes do seu integral cumprimento, ainda que se alegasse a excessiva onerosidade do ajuste para uma das partes (MIRANDA, 1962). 
Outra parte da doutrina, contudo, já defendia a possibilidade de utilização da onerosidade excessiva superveniente como fundamento para a intervenção no contrato, mesmo sem previsão legal, pela existência implícita da cláusula rebus sic stantibus (SILVA, 2014).

O mecanismo de revisão contratual com base na superveniência de alteração substancial da moldura fática original já era algo conhecido no Código de Hamurabi: "se alguém tem um débito a juros, e uma tempestade devasta o campo ou destrói a colheita, ou por falta d'água não cresce o trigo no campo, ele não deverá nesse ano dar trigo ao credor, deverá modificar sua tábua de contrato e não pagar juros por esse ano" (GONÇALVES, 2018, p. 99). Na Roma Antiga também já se enunciara que a obrigação deveria se condicionar à permanência do estado em que a promessa foi feita (MARQUES, 2007).

Na Idade Média, contudo, tal ideia foi sistematizada e difundida, assumindo a feição proposta no brocardo latino: Contractus qui habent tractum succesivum et dependentiam de futuro rebus sic stantibus intelliguntur ${ }^{1}$ (PEREIRA, 2014, p. 140). Nessa perspectiva, havia que se perquirir a relação entre o negócio jurídico entabulado e a realidade objetiva sobre a qual o ajuste fora firmado, a fim de se aquilatarem os influxos dos fatos supervenientes diante da vontade expressada pelos contratantes com base na primeira moldura fática, já que o cumprimento do pacto poderia se tornar inviável por fatos supervenientes que alterassem de forma substancial a base objetiva do negócio.

Vê-se, portanto, que a construção teórica da cláusula rebus sic stantibus não estava atrelada a uma investigação subjetiva acerca da capacidade de prever e prevenir os riscos do contrato por parte dos negociantes. Bastava a modificação substancial do contexto fático motivador do negócio para se cogitar da sua desvinculação ou modificação.

Foi na modernidade que a valorização da vontade das partes como elemento fundamental e intangível do negócio se apresentou como pilar rígido de interpretação dos contratos, inclusive da cláusula rebus sic stantibus, conforme previu o art. 85 do Código Civil de 1916: nas declarações de vontade se atenderá mais à intenção das vontades que à sua literalidade.

\footnotetext{
${ }^{1}$ Nos dizeres de Caio Mário da Silva Pereira: [o]s contratos que têm trato sucessivo e dependência futura devem ser entendidos estando assim as coisas.
}

Embora o cenário fosse hostil à teoria da imprevisão, os fatos supervenientes que tornavam impossível ou excessivamente oneroso o contrato entabulado, tais como as guerras, pestes e calamidades públicas, eram uma realidade incontornável, convidativa à aplicação da cláusula rebus sic stantibus, com uma roupagem moderna e protetora da vontade como valor da autonomia privada.

No direito comparado, a resposta ao problema da imprevisão excessivamente onerosa frente ao pacta sunt servanda rendeu ensejo a três teorias distintas, as quais operavam sob o mesmo signo de teorias da imprevisão, a saber: teoria da pressuposição, teoria da base subjetiva do negócio e teoria da base objetiva.

É certo que os dois grandes vetores das partes que ocupam os polos da relação contratual constituem-se em avaliar os riscos do negócio e a equivalência das suas respectivas prestações, operando-se de forma racional.

Nesse sentido, para a teoria da pressuposição, desenvolvida por Windsheid em 1900 na Alemanha, as partes pressupõem uma condição implícita de que as cláusulas pactuadas permanecem vinculativas se, no futuro, não se revelarem incompatíveis com 0 desejo de contratá-las. Nesse sentido, leciona Paulo Roberto Roque Antonio Khouri (2006, p. 16):

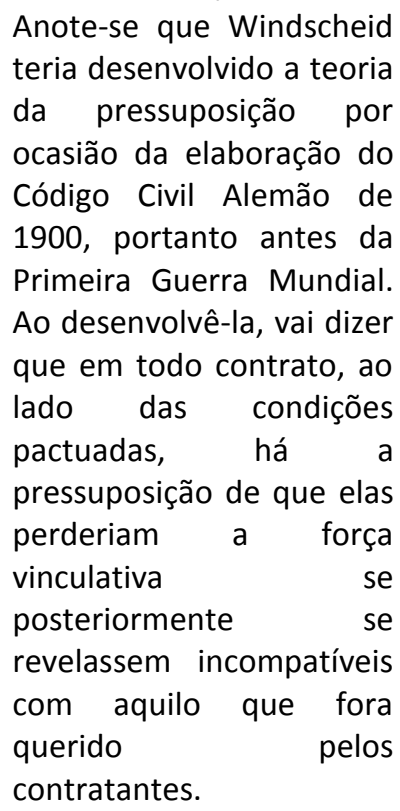

Portanto, em toda a contratação haveria um pacto pressuposto, aceito por uma ou ambas as partes, de que o limite da vontade de contratar era a própria manutenção do status objetivo quo ante. Em outras palavras, independentemente do que o outro contratante 
externasse a título de consentimento em relação à cláusula pressuposta, o negócio poderia deixar de ser vinculativo se o quadro fático se alterasse de forma substancial, o que poderia constituir verdadeira reserva mental (BESSONE, 1997). A teoria acabou sendo rejeitada pelo Código Civil alemão, dada a sua amplitude e possibilidade de perigo à segurança das operações jurídicas (KHOURI, 2006).

Ainda na esteira da pressuposição, a teoria da base subjetiva do negócio, liderada por Oertman, salienta que a cláusula de desvinculação superveniente pressuposta, representada mentalmente por uma ou ambas as partes, teria de ser aceita e conhecida, ainda que não expressa no contrato firmado. Com isso, tal como o contexto fático do negócio não está inteiramente expresso no pacto, porém é conhecido pelos agentes, a "base subjetiva", de conhecimento mútuo, também estaria contida nas dobras da relação e contava com a ciência e aceitação de ambas as partes. Uma vez alterados os parâmetros objetivos da avença, sua base subjetiva também estaria sujeita à ruptura, desvinculando-se os negociantes pelo expresso desejo de não contratar fora da realidade subjacente original conhecida. Como leciona Paulo Khouri (2006, p. 17): “eram necessários um conhecimento e uma aceitação comum daquela representação e então se formaria o que o próprio Oertman denominou 'base subjetiva do negócio'".

Numa postura crítica às teorias até então desenvolvidas, Karl Larenz apresenta a terceira teoria da imprevisão, fincando suas ideias na base objetiva do contrato e rejeitando a investigação psicológica dos contratantes ao tempo do ajuste e a insegurança jurídica que disso poderia defluir. Para aludido doutrinador, a teoria da base subjetiva ficava não só adstrita ao campo psicológico e íntimo das partes, de difícil decifração, mas também presa àquilo que elas eram capazes de conhecer como alteração da realidade objetiva apta a modificador a vontade do outro. Ora, se nenhuma das partes imaginasse a ocorrência de uma peste em um espaço de 30 dias da contratação e tal fator não fosse considerado por ambas como base subjetiva, o contrato, em tese, não poderia ser alterado. Além disso, a teoria criticada poderia dar margem ao açodado pedido de desvinculação, na medida em que qualquer desvio da realidade original poderia resvalar na vontade inicial das partes.
Assim, defendia-se na terceira corrente que o critério apto a justificar a alteração ou resolução do contrato por uma imprevisão excessivamente onerosa deveria ser direcionado para os fatos e circunstâncias da realidade que fossem efetivamente determinantes no momento da contratação original, os quais influenciavam de forma substancial, naquele momento, a decisão das partes quanto ao risco e à equivalência das prestações.

Dessa forma, a simples eleição das partes quanto à base subjetiva do negócio (pressuposição de que o contrato só vale diante da mesma moldura fática até então conhecida) não torna, por si só, o fato superveniente relevante para fins de alteração contratual, já que - evento novo haveria de abalar de forma objetiva as bases do contrato, sem espaços para a interpretação subjetiva das partes. Segundo a lição de Paulo Khouri (2006, p. 19), citando Larenz, a base objetiva é "um conjunto de circunstâncias cuja existência ou pertinência pressupõe o contrato, supondo ou não os contratantes".

De fato, a percepção da realidade por parte dos contratantes não é infalível; dessa forma, a vontade sequer pode ser exercida quanto à limitação de contratar frente a fatos estranhos e imprevisíveis ao homem de entendimento médio.

Nesse ângulo, a base objetiva constitui o bloco da realidade que, enquanto vigente, faz o contrato ser do modo como é e existir para os fins a que se presta, razão por que a sua alteração substancial é aquela que torna o contrato excessivamente oneroso e realmente autoriza o acionamento do instituto. Com isso, não se condiciona a teoria da imprevisão ao talante da base subjetiva do negócio, formada com base na percepção das partes quanto ao contexto original e alteração posterior, mas sim aos parâmetros fáticos essenciais que levaram os contratantes a definirem os termos ajustados ${ }^{2}$. Mantidos estes critérios fáticos, expressos ou não no contrato, ainda que sobrevenham eventos supervenientes de qualquer natureza, não há que se cogitar da excessiva onerosidade, porquanto a equivalência das prestações e a finalidade do negócio ainda se encontram no mesmo quadro objetivo original, vinculando plenamente os contratantes.

\footnotetext{
${ }^{2}$ Nota explicativa: Caso venha a ocorrer uma falsa percepção da realidade pré-existente ao negócio, a parte prejudicada poderá invocar o erro como um vício de consentimento.
} 
Segundo disserta Paulo Khouri (2006, p. 20):

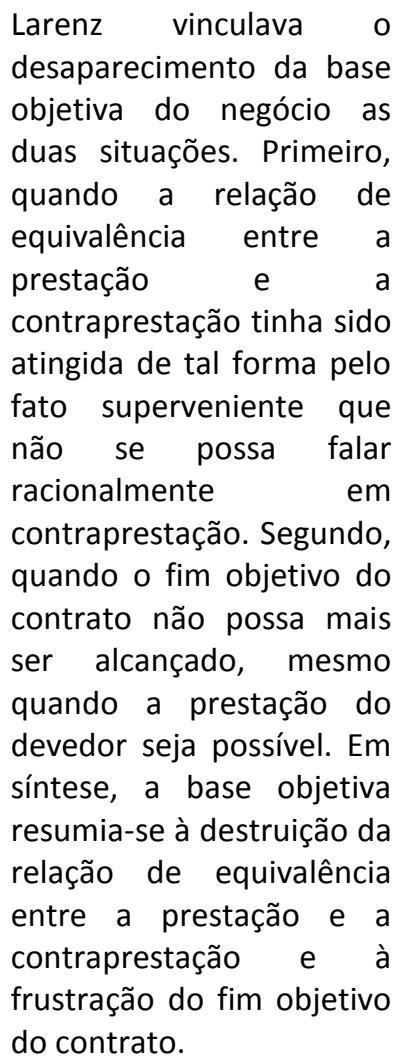

Embora a definição da base objetiva tenha contribuído para uma aplicação mais segura do instituto, algumas imprecisões ainda atormentariam seu implemento, já que não se pode conhecer em abstrato o que é efetivamente uma destruição da equivalência das prestações ou a frustração do fim objetivo do contrato, considerando que a sua finalidade pode ser interpretada de forma subjetiva. Nesse sentido, Larenz sustentou que a teoria da imprevisão não poderia ser aplicada se a alteração estivesse dentro da esfera de influência da parte prejudicada, se o prejudicado estivesse em mora no momento da ocorrência ou se o risco fosse expressamente assumido no contrato (KHOURI, 2006).

Embora crítica à base subjetiva, um ponto complexo e de difícil solução fez com que a teoria estudada cedesse à investigação subjetiva das partes no momento da contratação. Trata-se do problema relativo ao risco conhecido e não prevenido em contrato pelas partes, cuja ocorrência futura tem o condão de alterar a base objetiva do pacto. Para resolver a questão Larenz imputa àquele que sabia do risco e nada fez a respeito no momento da contratação o dever de absorver os danos supervenientes experimentados, justamente porque teria aceitado tais riscos de forma tácita, resignandose com a prestação dada num juízo de ponderação da possível realidade futura (KHOURI, 2006).

Evidente que o risco manifestamente passível de prevenção constitui desafio complexo à consolidação da teoria da base objetiva como critério para aplicação da onerosidade excessiva superveniente, porquanto prescinde de parâmetros objetivos para sua definição, o que deixa o julgador próximo do juízo de equidade no caso concreto.

No ordenamento jurídico brasileiro, a onerosidade excessiva superveniente foi positivada somente em 1990, com o advento do Código de Defesa do Consumidor, cujo artigo 6으, inciso V, dispõe: "a modificação das cláusulas contratuais que estabeleçam prestações desproporcionais ou sua revisão em razão de fatos supervenientes que as tornem excessivamente onerosas" (BRASIL, 1990, não paginado). Posteriormente, a Lei 8.666/1993 também positivou o instituto no âmbito dos contratos públicos, em seu art. 65, alínea "d". Por fim, o Código Civil de 2002 passou a disciplinar a matéria também, de modo que todas as regras positivadas incorporaram, em alguma medida, os fundamentos doutrinários expostos (TEPEDINO, 2001) $)^{3}$.

Apesar da positivação legal da onerosidade excessiva superveniente, o fato é que os conceitos jurídicos empregados são dotados de imprecisão e vazados em cláusulas abertas, razão por que o papel do julgador assume especial relevância.

Nesse panorama, o julgador se vê forçado à utilização da equidade como forma de corrigir as distorções provocadas pela excessiva onerosidade superveniente na tela dos contratos, porquanto a análise desemboca, em alguma medida, nos aspectos subjetivos da contratação. Tal mecanismo, contudo, não pode significar uma íntima convicção.

É nessa ordem de ideias que a jurisprudência assume papel de relevo no desafio proposto, já que interpreta o ordenamento jurídico e contribui com a formulação de vetores para a aplicação do instituto da excessiva onerosidade, notadamente em tempos de pandemia global, geradora de eventos

\footnotetext{
3 Nesse sentido, Fabiana Rodrigues Barletta assevera que o CDC adotou expressamente a teoria da base objetiva do negócio.
} 
imprevisíveis e acentuação de todos os riscos até então conhecidos pelas partes contratantes.

A Lei 13.874/2019, denominada Lei da Liberdade Econômica, trouxe palpáveis alterações na possibilidade de intervenção do Estado nos contratos e atividades econômicas em geral. Exemplo disso é o art. 2ㅇ, inciso IV, que prevê: a intervenção subsidiária e excepcional do Estado sobre o exercício de atividades econômicas (BRASIL, 2019).

Nessa perspectiva, tem-se clara a necessidade de que os parâmetros para intervenção judicial nos contratos em que ocorra a onerosidade excessiva superveniente tenham um formato objetivo, previsível e longe da insegurança jurídica. Tanto é assim que a Lei 14.010/2020, com a finalidade de regulamentar as relações privadas em tempos de pandemia (Covid-19), foi expressa em conter o instituto da onerosidade excessiva superveniente em seus artigos 60 e 7을 ao excluir a sua aplicabilidade diante da variação da moeda (inflação) e condicionar seus efeitos no tempo, dando-lhe apenas a eficácia ex nunc.

Conforme acentua Paulo Khouri (2006, p. 79):

O que coloca a doutrina te
desafio é a busca de
critérios objetivos que
possam englobar todas as
situações e levar a quebra
da base do negócio
jurídico sem que se
procurem deficiências na
vontade das partes.
Repetindo, aqui, a
afirmação de Menezes
Cordeiro, não se pode
imputar à vontade aquilo
que vir por
desconhecimento, ela
nunca poderia ter querido.

Daí a necessidade de estudo do tema em tempos de acentuada volatilidade econômica e social, a fim de aperfeiçoar o papel do direito na pacificação dos conflitos.

Natureza, espécies e regimes jurídicos da onerosidade excessiva

A onerosidade excessiva superveniente constitui forma de resolução ou modificação contratual, desde que preenchidos os pressupostos legais para o seu acionamento, o que pode ocorrer tanto por parte do devedor como do credor.
Para facilitar a compreensão do tema, divide-se a revisão judicial dos contratos em duas espécies, sendo a primeira denominada comum (onerosidade excessiva superveniente) e a segunda especial (KHOURI, 2006). Naquela, o instituto pode ser aplicado em uma gama generalizada de contratos, mesmo que diante de regimes jurídicos distintos (CC, CDC ou Lei de Licitações), enquanto a segunda modalidade revela-se aplicável a algumas espécies restritas de contratos nominados, cuja previsão vem regulamentada de maneira específica e se mostra aplicável única e exclusivamente à modalidade de ajuste tipificada em lei.

No campo das onerosidades excessivas comuns, destacam-se as hipóteses disciplinadas no Código Civil, em seus artigos 317, 478, 479 e 480, no Código de Defesa do Consumidor e na Lei 8.666/93 (Lei das Licitações).

Tal como já exposto, o Código Civil de 2002 trouxe consigo dispositivos de tratamento expresso à teoria da imprevisão:

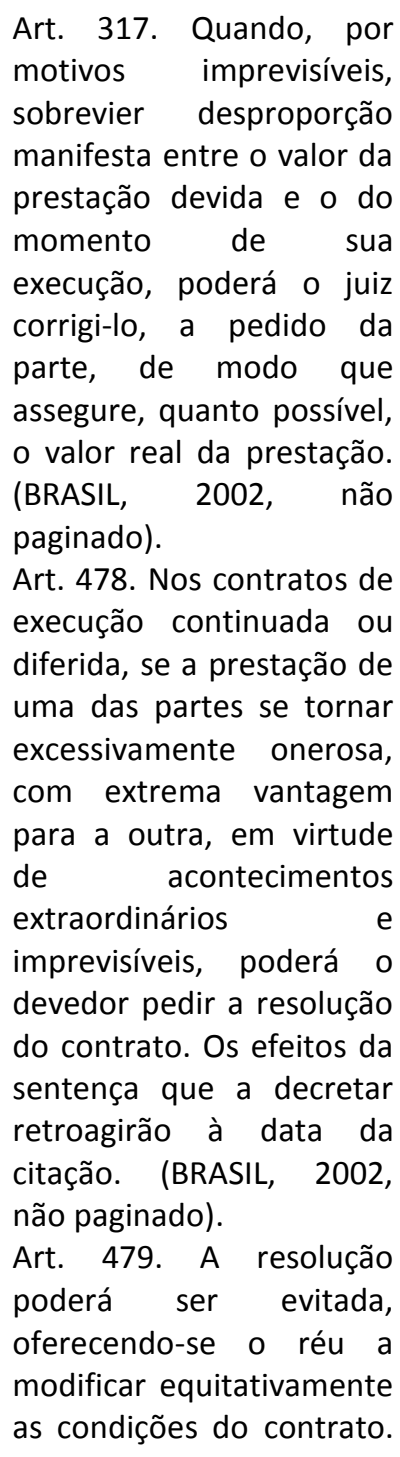


(BRASIL, 2002, não paginado).

Art. 480. Se no contrato as obrigações couberem a apenas uma das partes, poderá ela pleitear que a sua prestação seja reduzida, ou alterado o modo de executá-la, a fim de evitar a onerosidade excessiva. (BRASIL, 2002, não paginado)

O regime jurídico presente nos artigos acima expressos tem por traço comum uma ocorrência de onerosidade excessiva posterior ao contrato e não coberta pelos riscos deste, capaz de desiquilibrar a equação econômica do pacto, tudo em função de um fato extraordinário e imprevisível. De outro ângulo, o regime jurídico do CDC dispensa o pressuposto relativo ao fato extraordinário e imprevisível, razão pela qual será analisado a posteriori.

Ao que se extrai do art. 478 do CC, protege-se o equilíbrio contratual pelo instituto da onerosidade excessiva superveniente nos contratos de duração, nos quais as obrigações se protraem no tempo. Trata-se da matriz do instituto, por se tratar do dispositivo legal mais completo acerca dos pressupostos necessários à excessiva onerosidade superveniente.

Para o acionamento do instituto com base no dispositivo ora analisado exige-se que (i) o contrato seja de duração; (ii) haja um fato extraordinário e imprevisível no curso do cumprimento das obrigações; (iii) ocorra uma excessiva onerosidade em virtude do evento extraordinário e imprevisível; e (iv) em virtude desta excessiva onerosidade, uma das partes venha auferir extrema vantagem.

Embora conste do dispositivo a expressa menção à palavra devedor, não é este o único autorizado a requerer a aplicação da onerosidade excessiva superveniente, já que o credor da prestação também pode ser afetado pelo desequilíbrio contratual, pilar de toda construção do instituto, de sorte que se afigura plenamente válida a legitimidade daquele que ocupa o polo ativo da relação contratual de reclamar a aplicação da norma ao seu favor.

Tal posicionamento é defendido por Paulo Khouri (2006, p. 30):

[é] que o citato dispositivo se refere apenas ao termo devedor. Melhor técnico teria adotado o legislador brasileiro se tivesse como - legislador português, que, em vez de "devedor", empregou, no art. 437 de seu Código Civil, a expressão parte lesada [...] Referida situação representaria um injustificado privilégio para o devedor, ao passo que não só ele mas também o credor estão sujeitos a riscos consideráveis próprios ou extraordinários na execução do contrato.

Saliente-se que a disciplina do art. 478 é a mais abrangente do $\mathrm{CC}$, porquanto não se refere apenas e tão somente à calibragem da cláusula do preço como mecanismo de reequilíbrio contratual, o que permitiria a incursão em outros aspectos contratuais afetados pela onerosidade excessiva superveniente, tais como tempo e modo de pagamento.

De outro lado, o art. 317 do CC, apesar de carregar expressões equivalentes aos pressupostos do art. 478, traz diferenças sensíveis em relação ao seu paradigma. Com efeito, a norma em tela restringe-se à cláusula de preço e traz consigo a possibilidade de continuação do contrato por meio da simples modificação do ajuste original, enquanto o art. 478 se autolimita à resolução da avença.

A leitura conjugada dos dispositivos é essencial para a aplicação do instituto estudado, já que se complementam e alargam a possibilidade de reequilíbrio da relação contratual. Nas hipóteses mais abrangentes do art. 478, a resolução do contrato nem sempre pode se mostrar a melhor solução para a crise instaurada, porquanto é antiga a noção de que os contratos devem ser ao máximo preservados, em respeito à autonomia da vontade das partes. Tanto é assim que o art. 479 dispõe que "[a] resolução poderá ser evitada, oferecendo-se o réu a modificar equitativamente as condições do contrato" (BRASIL, 2002, não paginado).

Nessa perspectiva, se a continuidade do contrato depende da modificação de uma cláusula não relacionada ao preço, a fim de reequilibrar a relação frente à onerosidade excessiva superveniente, revela-se razoável que se faça uma alteração pontual, no lugar da 
resolução contratual como primeiro recurso disponível ao julgador.

Nessa linha, Orlando Gomes (1990, p. 42) assevera que "ocorrendo anormalidade da alea que todo contrato dependente de futuro encerra, pode-se operar sua resolução ou a redução das prestações."

Em outras palavras, é preferível que se alterem os elementos do contrato para mantê-lo a que se determine sua resolução de plano, quando ainda há meios para a sua preservação. Portanto, a frustração do fim negocial como efeito da onerosidade excessiva deve ser a última ratio, notadamente em função do princípio da máxima preservação da autonomia da vontade, ex vi do art. 2ㅇ, IV, da Lei 13.874/2019.

Nesse sentido, Carlos Roberto Gonçalves (2018, p. 33) defende que:

Malgrado o retrotranscrito art. 478 do Código Civil, concernente aos contratos bilaterais, permita somente a resolução do contrato, e não a sua revisão, esta pode, todavia, ser pleiteada com base no art. 317 do mesmo diploma, que estatui: "Quando, por motivos imprevisíveis, sobrevier desproporção manifesta entre o valor da prestação devida e o do momento de sua execução, poderá o juiz corrigi-lo, a pedido da parte, de modo que assegure, quanto possível, o valor real da prestação".

Tem-se, ainda, o art. 480 do CC, que estipula a aplicabilidade do tema estudado nos contratos unilaterais ou naqueles em que inexista o sinalagma, já que a obrigação de trato continuado se concentra, na letra do dispositivo, em relação a apenas uma das partes.

O legislador deixou claro que no ambiente dos contratos despossuídos do sinalagma a onerosidade excessiva superveniente pode ser aplicada, porquanto, independentemente da investigação quanto a equivalência das prestações, uma das partes pode se ver onerada de forma excessiva, a ponto de o cumprimento do negócio originalmente entabulado consistir num ato de sacrifício. Exemplo disso são os contratos gratuitos, tais como o comodato ou a doação. Trata-se de questão de isonomia, já que a disciplina do tema deve ter igual incidência nos contratos onerosos, gratuitos, bilaterais, unilaterais e sinalagmáticos ou não.

Nos casos em que a obrigação a ser cumprida por uma das partes for instantânea e de outro lado persistir o trato sucessivo para a outra, também há plena aplicabilidade da onerosidade excessiva superveniente, porquanto a característica do ajuste de duração ainda estaria presente em um dos polos do contrato.

Há que se analisar, ainda, o regime jurídico da onerosidade excessiva previsto no art. 6 , inciso $V$, do $C D C$, cuja parte final dispõe ser direito básico do consumidor a revisão das cláusulas contratuais "em razão de fatos supervenientes que as tornem excessivamente onerosas" (BRASIL, 1990, não paginado).

Tal como já exposto, a essência da revisão contratual em virtude da superveniência de excessiva onerosidade é a equivalência das prestações e o equilíbrio contratual, evitando-se o sacrifício de uma das partes diante de cenário que torna o pacto inviável da maneira como projetado, com base na moldura objetiva original.

Dessa forma, apesar de haver remissão expressa no Código Civil ao acionamento do instituto diante de fatos imprevisíveis ou extraordinários, o que realmente se deve perquirir, em sede de direito do consumidor, é se existe um evento superveniente que alterou a base objetiva do negócio, porquanto a investigação acerca da capacidade das partes de prever um fato extraordinário constitui subjetivação e imprecisão do tema a ponto de gerar mais insegurança.

A própria definição do que seja um fato extraordinário ou imprevisível constitui, por si só, desafio conceitual de difícil resolução no caso concreto, o que reclama mais subjetivismo na revisão judicial do contrato atingido pela onerosidade superveniente.

Por tais razões, assentou-se de forma majoritária na doutrina que, em verdade, seja no regime jurídico do $C C$ ou do $C D C$, a definição do que é um fato extraordinário ou imprevisível não constitui vetor primordial e obstativo na aplicação do instituto examinado, já que o fundamento da revisão é a alteração substancial da base objetiva do negócio, capaz de desequilibrar a relação contratual a ponto de reclamar intervenção judicial.

Nesse sentido: 
O atual fenômeno da objetivação do contrato exige que não sejam mais super valorizadas as intenções subjetivas das partes no momento da contratação. (...)

É exatamente este o propósito do artigo 60, inciso V, 2a parte, do Código de Defesa do Consumidor: considerar os elementos objetivos presentes naquele ambiente social, que fizeram com que o contrato perdesse a sua comutatividade ou sua finalidade, e viabilizar sua revisão a partir da equalização das prestações (TEPEDINO, 2001, p. 300).

É nessa perspectiva que o $C D C$, em seu art. 60 , inciso $V$, suprime a exigência de que se comprove um fato extraordinário ou imprevisível como requisito da revisão contratual com base na onerosidade excessiva, mesmo porque 0 consumidor, parte hipossuficiente na relação, provavelmente não reúne condições para avaliar de forma segura os riscos ordinários e todos os eventos previsíveis aptos a alterar a base objetiva do seu contrato. Nessa perspectiva, pode-se dizer que o CDC adotou de maneira expressa a teoria desenvolvida por Larenz:

Nesse sentido, este
dispositivo recebeu
influências da teoria da
quebra da base objetiva
de Larenz, avançando
ainda mais por
desconsiderar por
completo a previsibilidade
ou a imprevisibilidade das
transformações, firmando-
se, pois, no requisito
objetivo da excessiva
onerosidade
superveniente (TEPEDINO,
2001, p. 300).

Portanto, os requisitos exigidos pelo CDC para fins de aplicação da onerosidade excessiva são: (i) fato superveniente ao contrato e ligado à relação de consumo; (ii) evento não coberto pelos riscos do contrato; (iii) onerosidade excessiva, capaz de tornar a prestação manifestamente desproporcional e (iv) que a alteração do panorama fático superveniente cause vantagem ao fornecedor.

O risco contratual genuinamente coberto pelo negócio, ajustado de maneira clara e precisa com o consumidor, evidentemente não pode fundamentar o pedido de revisão judicial do ajuste firmado, já que o consumidor diante de qualquer alteração na moldura fática original poderia requerer o acionamento do instituto, mesmo que sua prestação já estivesse compatibilizada com o risco do evento futuro.

Tanto é assim que o art. 51, inciso III, do CDC, é expresso ao dispor que a onerosidade excessiva tem de ser enfrentada "considerandose a natureza e conteúdo do contrato, o interesse das partes e outras circunstâncias peculiares ao caso" (BRASIL, 1990, não paginado). Daí que o risco absolutamente previsível e presente na equação econômico-financeira do contrato não pode render ensejo à aplicação do instituto, cuja finalidade não pode ser a fraude ao princípio da força obrigatória dos contratos.

Por fim, ainda nas hipóteses comuns de onerosidade excessiva, aplicáveis às mais variadas formas de contrato, tem-se o regime jurídico do art. 65 da Lei 8.666/93, segundo o qual o contrato pode ser alterado para:

[...] restabelecer a relação que as partes pactuaram inicialmente entre os encargos do contratado e a retribuição da administração para a justa remuneração da obra, serviço ou fornecimento, objetivando a manutenção do equilíbrio econômicofinanceiro inicial do contrato, na hipótese de sobrevirem fatos imprevisíveis, ou previsíveis porém de conseqüências [sic] incalculáveis, retardadores ou impeditivos da execução do ajustado, ou, ainda, em caso de força maior, caso fortuito ou fato do príncipe, configurando álea econômica extraordinária e extracontratual (BRASIL, 1993, não paginado). 
A disciplina da onerosidade excessiva superveniente em sede de contratos públicos está em consonância com a positivação do instituto no Código Civil. Registre-se que o dispositivo da Lei de Licitações e Contratos Públicos é expresso no sentido de que o evento que torna $o$ contrato substancialmente atormentado pelo desequilíbrio não pode ser coberto pelos próprios riscos do negócio, já que se exige a configuração da álea econômica extraordinária e extracontratual.

Trata-se de importante remissão e que constitui, em verdade, fator a ser analisado em todas as espécies de onerosidade excessiva superveniente, porquanto funciona como um vetor fundamental para a avaliação, cabimento e efeitos do instituto no caso concreto. Com efeito, se os riscos ponderados pelas partes de forma prévia compuseram a prestação contratual e sua respectiva equivalência, fundamentando o equilíbrio contratual, a aplicação da onerosidade excessiva teria efeito reverso e serviria, assim, de subterfúgio e fonte de enriquecimento indevido.

A propósito, Enzo Roppo (1988, p. 262) leciona que:

A lógica, em suma, é sempre esta: cada contrato comporta, para quem o faz, riscos mais ou menos elevados; a lei tutela o contraente face aos riscos anormais, que nenhum cálculo racional económico permitiria considerar; mas deixa a cargo os riscos tipicamente conexos com a operação, que se inserem no andamento médio daquele dado mercado.

Paulo Khouri (2006, p. 61) também informa que: fato superveniente ou extraordinário, também não prescinde desse critério de valoração.

A expressa referência legal do art. 65 da Lei 8.666/93 à possibilidade de acionamento da onerosidade excessiva mesmo em caso de fatos previsíveis, porém de consequências incalculáveis, também elucida muito a compreensão do tema. Com efeito, a investigação acerca de ser o fato superveniente previsível ou não, bem como a necessidade de se definir se o evento que atormentou o equilíbrio do contrato é extraordinário ou oriundo de caso fortuito/força maior, constitui retorno ao momento em que as partes contrataram, tudo apto a gerar imprecisões e subjetivismos, já que são temas altamente disputados e passíveis de decisões díspares, em contexto de insegurança jurídica.

Por isso é que se defende a aplicação da onerosidade excessiva diante da alteração da base objetiva do negócio, desvinculando-se o condicionamento do instituto à definição de um fato extraordinário e imprevisível. Significa dizer que, uma vez alterados os elementos objetivos que fundamentaram a decisão de contratar e sobrevindo uma excessiva onerosidade, a intervenção judicial no contrato será autorizada, sem que se discuta acerca da natureza jurídica do evento, se imprevisível ou extraordinário. Portanto, o necessário é neutralizar o desequilíbrio contratual, afastando-se a distorção e injustiça que o pacto pode causar na esfera de direitos do prejudicado.

Nessa linha, Gustavo Tepedino (2001, p. 300) salienta que: "[n]uma sociedade de massas, o contrato deverá estar mais sensível 'ao que se manifesta no ambiente social, nas condições objetivas de mercado'".

Por fim, necessário expor as modalidades de revisão judicial das obrigações e contratos especiais, cuja disciplina legal envolve requisitos próprios de cada relação obrigacional.

Em linha de exposição simples, tem-se, por primeiro, o art. 1.699 do CC: "[s]e, fixados os alimentos, sobrevier mudança na situação financeira de quem os supre, ou na de quem os recebe, poderá o interessado reclamar ao juiz, conforme as circunstâncias, exoneração, redução ou majoração do encargo" (BRASIL, 2002, não paginado). 
No contrato de comodato, encontra-se previsão no art. 581, in fine, de revisão contratual específica para o comodante:

Art. 581. Se o comodato
não tiver prazo
convencional, presumir-
se-lhe-á o necessário para
o uso concedido; não
podendo o comodante,
salvo necessidade
imprevista e urgente,
reconhecida pelo juiz,
suspender o uso e gozo da
coisa emprestada, antes
de findo o prazo
convencional, ou o que se
determine pelo uso
outorgado. (BRASIL, 2002,
não paginado, grifo do
autor)

Quanto ao contrato de empreitada, o Código Civil estabelece em seu art. 620 que: "[s]e ocorrer diminuição no preço do material ou da mão-de-obra superior a um décimo do preço global convencionado, poderá este ser revisto, a pedido do dono da obra, para que se lhe assegure a diferença apurada" (BRASIL, 2002, não paginado).

Da mesma forma, o art. 770 do Código Civil estatui: "[s]alvo disposição em contrário, a diminuição do risco no curso do contrato não acarreta a redução do prêmio estipulado; mas, se a redução do risco for considerável, o segurado poderá exigir a revisão do prêmio, ou a resolução do contrato" (BRASIL, 2002, não paginado).

A Lei 8.245/91, em seu artigo 19, prevê disposição expressa quanto à possibilidade de alteração da cláusula de preço frente à variação mercadológica do imóvel: "[n]ão havendo acordo, o locador ou locatário, após três anos de vigência do contrato ou do acordo anteriormente realizado, poderão pedir revisão judicial do aluguel, a fim de ajustá-lo ao preço de mercado" (BRASIL, 1991, não paginado).

Uma vez expostas as premissas teóricas retiradas da doutrina e da legislação em vigor, propõe-se a análise de um bloco de julgados do Superior Tribunal de Justiça, o qual enfrenta a revisão judicial de contratos sob o prisma da excessiva onerosidade superveniente.

A análise que se propõe segue uma linha cronológica, partindo-se dos casos mais antigos para os mais recentes.
Revisão contratual decorrente da mudança inflacionária

O Superior Tribunal de Justiça, por meio do REsp 744.446-DF (informativo $\mathrm{n}^{\circ} 352$, STJ), de Relatoria do Min. Humberto Martins, decidiu em 2008 que, em um país como o Brasil, a inflação não pode ser tomada como álea extraordinária, de forma a possibilitar desequilíbrio contratual.

No caso em espécie, uma hidrelétrica firmou contrato com a administração pública em 1986 e sustentou que, durante a execução das obrigações que Ihe incumbia, foi surpreendida com inflação galopante nas décadas seguintes, o que teria tornado o contrato excessivamente oneroso, a ponto de tornar-se 0 seu cumprimento um verdadeiro sacrifício.

Importante discussão se colocou no início do acórdão analisado, já que se afirmou a possibilidade de aplicação da teoria da imprevisão mesmo nos contratos firmados antes do Código Civil de 2002 e da própria previsão do art. 65 da Lei 8.666/93, porquanto se trata de tema construído pelos intérpretes do Direito muito antes da sua positivação:

Teoria da Imprevisão. Alegada violação dos arts. 478,479 e 480 do novo Código Civil. De início, cumpre asseverar ser irrelevante o fato de que o contrato foi firmado antes da vigência do novo Código Civil para a análise da Teoria da Imprevisão. Questões principiológicas de que se valiam os intérpretes do próprio Código Beviláqua (STJREsp: 744.446-DF, Relator: Ministro Humberto Martins, Data de julgamento:17/04/2008, DJe: 05/05/2008, p. 1). (BRASIL, 2008).

Muito embora a inflação possa ser um fato superveniente que agrave a onerosidade do contrato para uma das partes, a sua ocorrência, na realidade brasileira (base objetiva do negócio), constitui acontecimento previsível e, portanto, um risco aceito pelas partes, levando em conta de forma mútua na composição do preço.

O relator do caso ainda salientou que: Não se mostra razoável o entendimento de que a inflação possa ser tomada, 
no Brasil, como álea extraordinária, de modo a possibilitar algum desequilíbrio na equação econômica do contrato, como há muito afirma a jurisprudência do STJ (STJREsp: 744.446-DF, Relator: Ministro Humberto Martins, Data de julgamento:17/04/2008, DJe: 05/05/2008, p.2). (BRASIL, 2008).

De fato, tal como exposto, o regime jurídico da onerosidade excessiva positivado no art. 65, alínea "d" da Lei 8.666/91 traz importante ressalva quanto ao acionamento do instituto nas hipóteses em que ocorrem as áleas econômicas ordinárias, entendidas como os riscos conhecidos e cobertos pelo próprio negócio. Com efeito, compõe a base objetiva do negócio o mútuo conhecimento da inflação galopante ou a possibilidade desta em período vindouro do contrato de duração, de modo que se embute na cláusula de preço o risco de variação dos insumos, caso nenhum índice tenha sido contratado pelas partes, razão pela qual a onerosidade excessiva superveniente não se verifica.

Outra importante decisão do STJ, forjada no REsp 1.321.614-SP (informativo $n^{\circ}$ 556), refere-se à possibilidade de revisão de contrato atrelado ao dólar, frente à maxidesvalorização do Real a partir de 1999, aplicando-se a teoria da imprevisão. Considerando que o atrelamento ao dólar da cláusula de preço é feito com a avaliação objetiva das partes do risco da flutuação do câmbio, o desequilíbrio contratual com fundamento em um perigo assumido pelas partes não pode servir de base para a onerosidade excessiva superveniente.

Desta forma, o Ministro Relator reconheceu que a intervenção do Poder Judiciário nos contratos cujas partes manifestamente assumem os riscos de um evento futuro constitui interferência indevida na autonomia da vontade. Assim, a Corte decidiu que, diante do cenário histórico de inflação e seus sucessivos influxos no padrão monetário brasileiro, o fenômeno não pode ser tomado como um fato superveniente fora do risco contratual pactuado pelas partes, já que o ajuste foi firmado com base na cotação norte-americana de forma consciente e voluntária.
Revisão contratual decorrente do aumento do preço da soja

Outro importante grupo de decisões do STJ diz respeito aos problemas advindos do fato conhecido como o caso das sojas verdes.

No curso do REsp no 803.481-GO, relatado pela Ministra Nancy Andrighi, os vendedores de soja alegaram que, obedecendo aos hábitos e costumes do negócio, firmaram contrato de venda a preço certo de safra futura de soja. Todavia, por fatos imprevisíveis, em especial a eleição presidencial e a iminente possibilidade de guerra no Oriente Médio, a prestação tornou-se absolutamente onerosa. Neste caso, na ânsia de equilibrar a relação, propuseram os agricultores a diminuição da cláusula de preço das sacas.

Extrai-se do caso que a decisão de primeiro grau não vislumbrou a possibilidade de revisão contratual, dada a característica de contrato aleatório firmado entre as partes. No entanto, entendeu o Tribunal de Justiça de Goiás que a alteração substancial do contrato de execução diferida não poderia o vendedor suportar tamanho prejuízo sozinho.

Por sua vez, a Ministra relatora destacou que, após a fugaz alta do dólar em 1999, não se poderia mais admitir que crises cambiais, causadas por guerras e outros eventos que impactam a economia global, constituíssem eventos imprevisíveis e não cobertos pelo risco do negócio no momento da contratação. Assim, concluiu que a volatilidade do dólar, além de evento previsível no momento do ajuste, ainda é elemento abalizado pelas partes na formação do preço, principalmente por se tratar de compra e venda de soja futura.

Conforme entendimento exposto no precedente analisado, no contrato de venda futura o vendedor garante o lucro mínimo e o suporta ante as variações dos preços no momento da entrega e, por outro lado, o adquirente sujeita-se a pagar o preço entabulado, mesmo que maior ao da cotação que antecede a colheita, sob o pálio da garantia do cumprimento da obrigação, a ser honrada nos moldes como foi contratada.

Nessa perspectiva, tem-se presente, mais uma vez, o risco avaliado e conhecido pelas partes como vetor fundamental para a aplicação do instituto, porquanto, a despeito da ocorrência de um evento futuro que onere uma das partes, a 
margem de perigo foi devidamente contratada e, portanto, deve ser absorvida pelos contratantes.

No mesmo segmento, entendeu o Ministro relator Luiz Felipe Salomão, no curso do REsp no 849.228 - GO, que por se tratar de produto cotado na bolsa de valores, não se poderia admitir a alta do dólar e o decorrente aumento nos preços da soja como evento imprevisível. Ponderou, por fim, que as partes no momento de entabular o contrato acordam e assumem a divisão equitativa dos riscos, não sendo legítima, nesses termos, a alteração do contrato de forma coativa.

Da mesma forma, no REsp 936.741/GO, o STJ reafirmou o entendimento de que em contratos de compra e venda futura de soja a preço fixo, a sucessiva alta dos preços não caracteriza excessiva onerosidade, mas tão somente lucratividade menor para a parte que, devendo conhecer as tormentas e as áleas do contrato, não se atentou.

Impertinência dos aspectos subjetivos da contratação para fins de onerosidade excessiva

Consolidando o posicionamento doutrinário já exposto quanto a impertinência de se avaliarem as circunstâncias subjetivas do negócio para fins de análise da onerosidade excessiva, decidiu o Superior Tribunal de Justiça, no âmbito do REsp no 447.336-SP, de relatoria da Min. Nancy Andrighi, que:

A onerosidade excessiva deriva exatamente de um fato objetivo, qual seja, a existência ou não de desproporção econômica entre a prestação da arrendadora e contraprestação ofertada pelo arrendatário. [...] Se o desequilíbrio contratual fato objetivo que é - é o quanto basta para a intervenção judicial, não influi na hipótese a análise de fatos subjetivos, tais como a capacidade econômico-financeira do arrendatário ou a data específica em que foi proposta a demanda, se 1 mês, 6 meses ou 2 anos após a ocorrência do fato causador do desequilíbrio (STJ, REsp 447.336-SP, Relator: Ministra Nancy Andrighi, Data de
Julgamento:11/04/2003,

DJe: 26/05/2003, p. 3).

Nos moldes do que já fora exposto acerca das premissas doutrinárias, não se pode considerar as circunstâncias subjetivas dos contratantes para fins de acionamento do instituto, já que a teoria da base objetiva do negócio preconiza que a realidade subjacente mais relevante para se avaliar o cabimento da onerosidade excessiva é aquela que envolve o contexto externo às partes no momento da contratação. Alterado este, não importa a investigação das condições subjetivas patrimoniais das partes, porquanto se avalia o desequilíbrio do contrato em si, bem como os riscos assumidos no momento da contratação, sem se imiscuir na condição patrimonial dos envolvidos.

Revisão contratual decorrente da doença ferrugem asiática em plantações

Outro importante precedente a ser analisado é a possibilidade de a ferrugem asiática ser tratada como evento imprevisível apto a gerar onerosidade excessiva sobre os contratos rurais. Neste sentido, destaque-se o Recurso Especial no 945.166 - GO (informativo $n^{\circ} 155$ STJ), relatado pelo Ministro Luis Felipe Salomão.

Em resumo, argumentava o agricultor que a baixa produtividade da soja decorrente da ferrugem asiática e a seguida alta do dólar americano elevaram os preços de insumos. Nesse sentido, o Ministro Relator assentou que a elevação do preço da soja é fato previsível no momento da ratificação contratual, sob a perspectiva de que a comercialização é realizada na bolsa de valores, sujeita, portanto, às demandas internacionais e aos riscos delas decorrentes. Em acréscimo, o Ministro Relator salientou que a ferrugem asiática possui certa previsibilidade, pois é uma doença que atinge as lavouras desde 2001. Não obstante, realçou que a praga na safra de 2003/2004 sequer foi tão gravosa como a experimentada em eventos anteriores.

Logo, a Corte reiterou que nos contratos de compra e venda futura de soja as variações de preço, por si só, não motivam a resolução contratual com base na teoria da imprevisão. Ademais, a ferrugem asiática não constitui fato superveniente imprevisível e extraordinário sem cobertura pelos riscos contratuais pactuados originalmente. 
Revisão contratual decorrente de desemprego ou redução de renda

Conforme o julgamento do AREsp no 1340.589 do Superior Tribunal de Justiça, a perda de emprego constitui evento previsível e ordinário, de modo que não enseja a quebra contratual.

No caso referido, postulou-se a revisão contratual de financiamento imobiliário conjugada com o alongamento do prazo de liquidação das parcelas, com fulcro na onerosidade excessiva prevista no Código de Defesa do Consumidor. O Tribunal de Justiça de origem não reconheceu a presença de fato imprevisível ou extraordinário que tornasse excessivamente onerosa a liquidação contratual, não se justificando o eventual desemprego ou redução de renda como circunstância chave.

Em síntese, o Código de Defesa do Consumidor permite a modificação ou a revisão das cláusulas contratuais que estabelecem prestações desproporcionais ao consolidado no contrato. Todavia, conforme evidencia a jurisprudência dominante do STJ, a efetiva caracterização da onerosidade excessiva demanda a ocorrência de superveniente fato extraordinário, que afete a base objetiva do contrato, desequilibrando a relação. Logo, por não encontrar fundamento em si mesmo, o agravo em Recurso Especial foi negado.

\section{CONSIDERAÇÕES FINAIS}

A onerosidade excessiva superveniente constitui-se como causa de resolução ou modificação contratual, cujos requisitos são: (i) contrato de duração; (ii) fato superveniente, extraordinário ou imprevisível [na hipótese prevista no art. 478 do Código Civil] (iii) excessiva onerosidade que cause desequilíbrio substancial no contrato; (iii) ausência de pactuação explícita ou implícita do risco.

Ao que se extrai dos casos selecionados na jurisprudência do Superior Tribunal de Justiça, os reclamos sustentados pelos contratantes afetados pela onerosidade superveniente, na maioria das vezes, fundavam-se no próprio risco contratual assumido ao tempo do ajuste, não se admitindo a revisão contratual baseada em onerosidade excessiva.

O equilíbrio do contrato é projetado, originariamente, na maior parte das vezes, com base no risco potencial decorrente de alterações no cenário econômico, social e político. De conseguinte, as variações da moeda, empregabilidade, crises internacionais e de saúde pública, ainda que assumam a roupagem de fatos supervenientes, necessitam ser analisadas à luz da margem de equilíbrio econômico desenhada pelas partes, considerando os perigos advindos das transformações do cenário objetivo até então conhecido. O risco contratual e sua importância na formação da equação econômica do contrato deve ser considerado como vetor de suma relevância para acionamento da onerosidade excessiva.

Ainda que as crises econômicas provoquem efeitos imediatos na produção legislativa, visando regular as situações emergenciais e transitórias, o julgador deve prezar pela neutralização do desequilíbrio superveniente do contrato com base em critérios objetivos, acompanhando, quando pertinente, a jurisprudência já formada, evitando-se interferência na autonomia privada fora dos limites juridicamente aceitáveis.

Desse modo, embora se reconheça que a pandemia de Covid-19 tenha causado um desmedido colapso econômico e que os cidadãos brasileiros não pudessem prever ou evitar os seus efeitos, há que se ter cautela na definição das hipóteses mais sensíveis de onerosidade excessiva superveniente. Reconhecido isso, prioriza-se a segurança jurídica das relações econômicas expressadas nos contratos e prestigia-se a autonomia privada.

\section{REFERÊNCIAS}

BESSONE, Darcy. Do contrato: teoria geral. 4. ed. São Paulo: Saraiva, 1997.

BRASIL. Presidência da República. Lei no 10.406, de $\mathbf{1 0}$ de janeiro de 2002. Institui o Código Civil. Brasília: Casa Civil, 2002. Disponível em: http://www.planalto.gov.br/ccivil_03/leis/2002/I 10406compilada.htm. Acesso em: 08 out. 2020.

BRASIL. Presidência da República. Lei no 8.666, de 21 de junho de 1993. Institui normas para licitações e contratos da Administração Pública e dá outras providências. Brasília: Casa Civil, 1993. Disponível em: http://www.planalto.gov.br/ccivil 03/leis/18666c ons.htm. Acesso em: 08 out. 2020.

BRASIL. Presidência da República. Lei no 8.245, de 18 de outubro de 1991.

Dispõe sobre as locações dos imóveis urbanos e os procedimentos a elas pertinentes. Brasília: 
Casa Civil, 1991. Disponível em: http://www.planalto.gov.br/ccivil_03/leis/18245. htm. Acesso em: 08 out. 2020.

BRASIL. Presidência da República. Lei no 8.078, de 11 de setembro de 1990. Dispõe sobre a proteção do consumidor e dá outras providências. Brasília: Casa Civil, 1990. Disponível em:

http://www.planalto.gov.br/ccivil_03/leis/18078c ompilado.htm. Acesso em: 08 out. 2020.

BRASIL. Superior Tribunal de Justiça. Ação Revisional. Contrato de financiamento Habitacional. SFH. Revisão de Parcelas. Redução da renda. Agravo em Recurso Especial no 1340.589/SE. Agravante: Allan da Rocha e Silva, Defensoria Pública da União. Agravado: Caixa Econômica Federal. Relator: Ministro Raul Araujo. Sergipe, 23 de abril de 2019. Disponível em: https://ww2.stj.jus.br/processo/revista/documen to/mediado/?componente=ITA\&sequencial $=1816$ 230\&num_registro $=201801971460 \&$ data $=20190$ 527\&formato=PDF. Acesso em: 14 out. 2020.

BRASIL. Superior Tribunal de Justiça. Omissão. Inexistência. Contrato de Compra e venda de Safra futura de soja. Contrato que também traz benefício ao agricultor. Ferrugem asiática. Doença que acomete as lavouras de soja no Brasil desde 2001, passível de controle pelo agricultor. Resolução do contrato por onerosidade excessiva. Impossibilidade. Oscilação de preço da "Commodity". Previsibilidade no panorama contratual. Recurso Especial no 945.166 - GO. Recorrente: $A B C$ Indústria e Comércio $S / A A B C$ INCO. Recorrido: Gilclésio Antônio Fernandes da Silva. Relator: Ministro Luís Felipe Salomão. Goiás, 28 de fevereiro de 2012. Disponível em: https://ww2.stj.jus.br/processo/revista/documen to/mediado/?componente=ITA\&sequencial $=1125$ 109\&num_registro $=200700922864 \&$ data $=20120$ 312\&formato=PDF. Acesso em: 14 out. 2020.

BRASIL. Superior Tribunal de Justiça. Ação Revisional de contrato de compra e venda. Dólar Americano. Maxidesvalorização do real. Aquisição de equipamentos para atividade profissional. Ausência de relação de consumo. Teorias da imprevisão. Teoria da onerosidade excessiva. Teoria da base objetiva. Inaplicabilidade. Recurso Especial no 1.321.614SP. Recorrente: Javier Figols Costa. Recorrido: General Eletric Company. Relator: Ministro Paulo de Tarso Sanseverino. São Paulo, 16 de dezembro de 2014.2 Disponível em: https://ww2.stj.jus.br/processo/revista/documen to/mediado/?componente=ITA\&sequencial $=1366$ $618 \&$ num_registro $=201200888764 \&$ data $=20150$ 303\&formato=PDF. Acesso em: 14 out. 2020.

BRASIL. Superior Tribunal de Justiça. Litigância de má-fé. Licitação. Contrato. Construção Hidrelétrica. Prejuízos sofridos pelo licitante durante a execução do contrato. Inflação. Proposta do licitante mal calculada. Álea ordinária que não pode ser atribuída à administração. Teoria da Imprevisão. Nãoaplicação. Doutrina e jurisprudência. Recurso Especial no 744.446 - DF. Recorrente: Mendes Junior S/A e Outro. Recorrido: Centrais Elétricas do Norte do Brasil S/A Eletronorte. Relator: Ministro Humberto Martins. Brasília, 17 de abril de 2008. Disponível em: https://ww2.stj.jus.br/processo/revista/documen to/mediado/?componente=ITA\&sequencial=7735 40\&num_registro $=200500662867 \&$ data $=200805$ 05\&formato=PDF. Acesso em: 14 out. 2020.

BRASIL. Superior Tribunal de Justiça. São Paulo. Ação de conhecimento sob o rito ordinário. Contrato de arrendamento mercantil. Cláusula de indexação pela variação do dólar norteamericano. Pacto de 24 parcelas. Incidência de excessiva desvalorização cambial da moeda brasileira a partir da 10 a parcela. Propositura da demanda após o pagamento da penúltima parcela. Possibilidade. Circunstância que não altera a excessiva onerosidade verificada. Recurso Especial no 447.336-SP. Recorrente: Nacer Abdo Dalul. Recorrido: Sudameris Arrendamento Mercantil S/A. Relator: Ministro Carlos Alberto Menezes Direito. São Paulo, 11 de abril de 2003. Disponível em: https://ww2.stj.jus.br/processo/revista/documen to $/$ mediado/?componente $=$ ATC\&sequencial $=604$ 508\&num_registro $=200200839500 \&$ data $=20030$ $526 \&$ tipo $=3 \&$ formato=PDF. Acesso em: 14 out. 2020.

BRASIL. Superior Tribunal de Justiça. Compra e venda de safra futura a preço certo. Alteração do valor do produto no mercado. Circunstância previsível. Onerosidade excessiva. Violação aos princípios da função social do contrato, boa-fé objetiva e probidade. Inexistência. Recurso Especial no 803.481-GO. Recorrente: Cargill Agrícol S/A. Recorrido: Luiz Ferreira Lima. 
Relatora: Nancy Andrighi. Goiás. 28 de junho de $2007 . \quad$ Disponível em: https://jurisprudencia.s3.amazonaws.com/STJ/IT /RESP_803481_GO_1271740296762.pdf?AWSAcc essKeyld=AKIARMMD5JEAD4VJ344N\&Expires $=16$ 02557818\&Signature $=U A c 5 h 4 f j \% 2 B j 01 J n H G Z U b r$ yZoJEM\%3D. Acesso em: 14 out. 2020.

GOMES, Orlando. Contratos. 12. ed. Rio de Janeiro: Forense, 1990.

GONÇALVES, Carlos Roberto. Curso de Direito Civil. São Paulo: Saraiva, 2018. v. 3.

HENRIQUES, Antonio; MEDEIROS, João Bosco. Metodologia científica na pesquisa. 9. ed. São Paulo: Atlas, 2017.

MARCONI, Marina de Andrade; LAKATOS, Eva Maria. Fundamentos de metodologia científica. 8. ed. São Paulo: Atlas, 2019.

MARQUES, Claudia Lima. A nova crise do contrato (coord.). São Paulo: Revista dos Tribunais, 2007.

MEZZAROBA, Orides; MONTEIRO, Cláudia Servilha. Manual de metodologia da pesquisa no direito. 8. ed. São Paulo: Saraiva Educação, 2019.

MIRANDA, Pontes de. Tratado de Direito Privado, 2. ed. Rio de Janeiro: Borsoi, 1962, tomo 25.

KHOURI, Paulo Roberto Roque Antonio. A revisão judicial dos contratos no novo Código Civil, Código de Defesa do Consumidor e Lei 8.666/93: a onerosidade excessiva superveniente. São Paulo: Atlas, 2006.

PEREIRA, Caio Mário da Silva. Instituições de Direito Civil. 18. ed. Rio de Janeiro: Forense, 2014. v.3.

ROPPO, Enzo. O contrato. Coimbra: Livraria Almedina, 1988.

TEPEDINO, Gustavo (coord.). Problemas de Direito Constitucional. Editora Renovar: Rio de Janeiro,2001. 